\title{
O papel da linguagem do pesquisador na construção da compreensão de um texto
}

\author{
Angela Maria Oliveira Santa-Clara \\ Tícia Cassiany Ferro \\ Sandra Patrícia Ataíde Ferreira \\ Universidade Federal de Pernambuco
}

\begin{abstract}
Resumo
No presente artigo, discute-se o papel da linguagem do pesquisador dentro da perspectiva sócio-interacionista, contestando-se o pressuposto de neutralidade tradicionalmente a ela atribuído. Visa-se verificar a interferência das intervenções verbais de uma pesquisadora sobre a construção da compreensão textual de uma criança de dez anos de idade, que freqüentava a $4^{\underline{a}}$ série do Ensino Fundamental de uma escola privada do Recife. A atividade de compreensão textual era composta de uma narrativa acompanhada de sete perguntas. A criança lia a narrativa e respondia oralmente às perguntas realizadas pela pesquisadora. A partir de uma análise qualitativa de uma seqüência de diálogo, verificou-se que os movimentos discursivos permitiram, por um lado, a fuga do roteiro previamente estabelecido pela pesquisadora e, por outro, e mais importante, a mudança qualitativa na representação textual inicialmente construída pela criança.
\end{abstract}

Palavras-chave: linguagem; interação verbal; compreensão textual; construção de conhecimento

\begin{abstract}
The role of the researcher's way of speaking on the construction of text comprehension. In the present paper the researcher's way of speaking is discussed from a perspective of social interaction, thus contesting the assumption of neutrality that has traditionally been attributed to it. The main purpose is to verify the influence of a researcher's verbal interventions on the construction of text comprehension of a ten-year-old fourth grade student at a private school in the city of Recife. A narrative followed by seven questions composed the text comprehension task. The student was told to read the narrative and then to answer the researcher's questions orally. A qualitative analysis of the dialogue between student and researcher showed that the discursive movements that occurred during the interaction led to two significant changes: first, the researcher was able to break from the previously established routine; and second, there was a qualitative change on the textual representation initially constructed by the child. The latter of the two changes is seen as important evidence contradicting the assumption of language neutrality.
\end{abstract}

Keywords: language; verbal interaction; text comprehension; knowledge construction

$\mathrm{U}$ m número significativo de estudos realizados no âmbito da psicologia científica faz uso de procedimentos metodológicos que se apóiam na linguagem, tais como entrevistas clínicas, questionários, etc. Grande parte deles o faz ancorando-se em um pressuposto de neutralidade desta ferramenta, e isso significa que, mesmo de modo nãoconsciente ou não-explícito, consideram a linguagem simplesmente como um instrumento de comunicação e de representações mentais internas dos indivíduos.

Como consequiência desse modo de conceber a linguagem, durante a preparação de tais estudos, são elaboradas instruções para serem transmitidas aos participantes do modo mais uniforme possível, ou seja, sem que estas sofram alterações entre um participante e outro. Tal procedimento visa controlar a variável "linguagem" que, da parte do pesquisador, servirá apenas como meio de prover instruções uniformes que levem o participante à realização da tarefa sendo proposta e que, da parte deste último, será o instrumento através do qual serão explicitados os processos psicológicos que estão sendo investigados.

Nessa perspectiva, o caráter dinâmico da comunicação oral referente à situação ou contexto comunicativo, parece ser ignorado. Há uma espécie de ilusão de estabilidade do setting de pesquisa (especialmente quanto aos elementos sujeito e pesquisador), como se estes não sofressem modificações ao longo do tempo. Dito em outras palavras, age-se como se fosse possível reproduzir as mesmas condições de um contexto comunicativo, em momentos temporais diferen- 
tes. Isto remete ao conceito de novidade adotado por Valsiner (2000), quando da discussão de sua perspectiva de desenvolvimento, na qual destaca a irreversibilidade do tempo, referindo-se à impossibilidade de um indivíduo retornar às experiências previamente vividas. As pessoas, segundo o autor, projetam-se para o futuro, construindo-o no momento presente, a partir de reconstruções do que aconteceu no passado.

Para Valsiner (2000), os seres humanos - precisamente devido à indeterminação do seu futuro - usam dispositivos psicológicos para criar imagens de estabilidade para o mesmo. Neste processo psicológico de construção, é omitido o caráter único de cada experiência vivida, numa tentativa de construir o curso de eventos da vida como sendo previsíveis, repetidos e conhecidos. Isto é uma ilusão psicológica construída, oriunda da necessidade de adaptação a um meio ambiente em constante mudança. Mas, se, por um lado, esta pode ser tomada como uma ilusão adaptativa e necessária à vida psicológica humana, por outro, ela torna os indivíduos "cegos" aos aspectos de suas relações com o meio ambiente que tornam o desenvolvimento possível: as novidades.

Diante disso, conclui-se que ainda que todos os cuidados sejam tomados para que os mesmos elementos de uma situação de "laboratório" estejam presentes nos diferentes momentos de uma pesquisa, isso provavelmente não ocorrerá. A própria introdução de um novo participante trará nuances diferenciadas à interação que irá se desenrolar naquele ambiente. Os acontecimentos a que o pesquisador e o participante são submetidos nos diferentes contextos comunicativos de que fazem parte (família, escola, trabalho, etc.), entre um momento e outro da pesquisa, deixam marcas (novidades) que são levadas para a situação de pesquisa e que, a despeito dos cuidados de controle que possam ser tomados, irão alterar o setting comunicativo. Isto sugere que, até mesmo o pesquisador apresenta-se como uma novidade nos diferentes momentos de sua coleta de dados, uma vez que a consistência de sua própria subjetividade está em permanente mudança.

É compartilhando dessa perspectiva de desenvolvimento em que a linguagem tem um papel relevante como constituinte do pensamento humano, que se concebe a análise comunicativa como a mais provável de capturar as mudanças ocorridas no plano microgenético. Tais mudanças, uma vez capturadas, tornarão evidente a impossibilidade de se considerar a linguagem como neutra, passível apenas de tornar visíveis estados mentais internos do indivíduo. Diante disso procederemos a uma reflexão sobre o papel constitutivo da linguagem.

\section{O papel constitutivo da linguagem}

Antes que se possa fazer qualquer teorização a respeito do papel constitutivo da linguagem, é necessário que se faça uma reflexão a respeito da concepção de linguagem que está sendo adotada no presente estudo. Tal procedimento se faz necessário pelo fato de que diferentes concepções remetem a diferentes abordagens teóricas, o que por sua vez terá um papel decisivo no tipo de análise a ser realizado.
Koch (1997) destaca três diferentes concepções de linguagem: (1) linguagem como representação do pensamento e espelho da mente; (2) linguagem como ferramenta de comunicação e (3) linguagem como ação e interação.

$\mathrm{Na}$ concepção de linguagem como representação do pensamento, esta é vista como algo que serve para acessar o conhecimento já existente na mente do indivíduo, como se ele fosse estanque e a linguagem em si mesma não contribuísse para a sua constituição. Nessa perspectiva, a ênfase analítica incide sobre o produto final, descartando o processo e o caráter social do desenvolvimento. Como menciona Palangana (1994), a psicologia acreditou durante séculos que as explicações para os processos psicológicos deveriam ser buscadas apenas no interior do próprio sujeito, fato que até hoje ainda se verifica em várias vertentes desta ciência que não enfatizam o papel das relações sociais sobre o desenvolvimento.

A segunda concepção é a de linguagem como ferramenta de comunicação, na qual lhe é atribuída a função de transmissão de informações do emissor para o receptor, em que a comunicação efetiva depende basicamente do processo de codificação e decodificação da linguagem. Então, é estabelecido que através da linguagem o indivíduo irá transmitir suas intenções comunicativas, tal como estão representadas na sua mente.

Já a concepção de linguagem como ação e interação, presente em muitos estudos da psicologia contemporânea, dá ênfase ao papel da linguagem na construção do conhecimento, apoiando-se primordialmente nos pressupostos de Vygotsky (1996), nos quais a linguagem é vista como o principal instrumento de mediação semiótica, responsável pela internalização das funções psicológicas superiores.

A mediação semiótica dá lugar ao processo de internalização que é desenvolvido pelo mecanismo de socialização dos indivíduos. Este mecanismo, ponto chave da teoria de Vygotsky, explica a íntima conexão entre a natureza social das funções psicológicas de ordem superior, que diferentemente das funções elementares, fazem uso dos signos. O que torna possível o processo de internalização é, exatamente a natureza semiótica das interações comunicativas entre as pessoas, pois o contato com formas mediadas de atividade psicológica que se dá durante estas interações é o que possibilita a recriação no plano interno, destas formas externas de atividade.

Sendo assim, na teoria de Vygotsky a linguagem não tem somente o papel de instrumento/ferramenta, mas possui principalmente o papel constituinte de todas as funções psicológico superiores; para ele os instrumentos de trabalho são importantes para o processo de hominização ${ }^{1}$, mas é o uso de signos que modifica toda atividade psicológica. Portanto, o papel desempenhado pela linguagem não é apenas de instrumento/ferramenta de comunicação. A linguagem é uma atividade sócio-cultural, intersubjetiva, sendo o outro o elemento central na constituição do pensamento. Nessa visão, a linguagem é concebida como atividade compartilhada entre os interlocutores. 
Pensando no processo de aprendizado, conseqüentemente de desenvolvimento, como atividade compartilhada, Vygotsky (1996) criou o conceito de Zona de Desenvolvimento Proximal (ZDP). Na ZDP o processo de internalização depende da interação social do aprendiz com outro mais capaz. Inspirado nesse conceito, Bruner (1985) tenta compreender o processo de desenvolvimento e aprendizado de crianças com ajuda de tutores mais capazes. Para Bruner, o tutor tem a função de scaffolding, permitindo à criança internalizar conhecimentos externos e convertê-los em ferramentas de controle consciente.

Em consonância com os postulados de Vygotsky, Bakhtin (2002), considera que o psiquismo do indivíduo se constitui através do material semiótico. Seus pressupostos surgiram como uma tentativa de responder a questões referentes à relação entre mente (self) e mundo; e entre mente (self) e o outro, tratando o signo como a interseção entre o intrapsicológico e o interpsicológico. Portanto, na constituição da consciência, Bakhtin destaca as múltiplas vozes, formadas nos cenários sociais, culturais e institucionais. Nessa perspectiva, a linguagem/texto é um fenômeno complexo e dialógico, constituído no "tecido de muitas vozes" (textos/ discursos), que se completam, se respondem e se polemizam em seu próprio interior.

No que concerne à interlocução, Smolka (1995) defende que a atividade de compreensão é mais complexa do que a de produção, pois implica em compreender pensamentos, motivos, desejos. Nessa direção, as meias palavras e o não dito precisam ser interpretados e desvelados para que haja compreensão por parte do indivíduo, porque nem tudo está explicitado no texto. Em outras palavras, os interlocutores para compreenderem um texto oral ou escrito precisam levar em consideração as múltiplas vozes presentes no discurso, fazendo inferências possibilitadas por esta característica polissêmica da linguagem.

\section{Compreensão textual}

Nas situações comunicativas, a busca da compreensão é o objetivo principal. Nessas situações, o indivíduo tanto pretende se fazer compreender como ser compreendido. Para alcançar tal objetivo, os participantes do discurso negociam os significados compartilhados, desvelando os sentidos implícitos na mensagem veiculada dentro de um contexto de produção. Deste modo, como diz Orlandi (1996), o contexto é constitutivo do sentido, já que a variação nas condições de produção afeta a construção de significados que emergem a partir da interação entre interlocutores.

É na interação com o outro, em um contexto particular, que os significados são construídos, desconstruídos e reconstruídos, favorecendo a emergência de uma situação propícia à mudança psicológica dos indivíduos envolvidos no processo de comunicação oral ou escrita.

No que se refere à comunicação escrita, caracterizada pela defasagem de tempo entre a produção e a recepção da mensagem, o leitor precisa restaurar e recuperar a força do enunciado pretendida pelo autor (Olson, 1997) a partir de uma relação ativa e dialética com o texto, em que tanto o modelo de mundo do autor como o do leitor são necessários para que a compreensão se efetive.

Acredita-se, deste modo, que nem o texto nem o leitor mostram-se, por si só, como condição suficiente para garantir a construção de significado veiculado pelo primeiro. Pelo contrário, defende-se que ambos são necessários e que a reelaboração do significado pretendido pelo autor é influenciada sobremaneira pela história cognitiva e afetiva do leitor.

Compartilha-se com Geraldi (2000) a idéia de que a leitura é um processo de interlocução entre leitor e texto, em que o primeiro modifica-se e modifica o texto através da reconstrução do significado por ele veiculado. Desta interação, múltiplos significados podem ser elaborados, já que este processo não é dominado unicamente pelo autor, mas depende dos objetivos e conhecimentos prévios do indivíduo que está lendo o texto.

Pensa-se, portanto, que o ato de leitura pode acarretar mudanças profundas no leitor, permitindo um afastamento e análise do real enquanto objeto de investigação, e a possibilidade de perceber as relações por detrás das circunstâncias e situações. Como diz Foucambert (1997), o acesso ao escrito (e não ao inscrito!) permite a verificação, elaboração e mudanças de pontos de vista, colocando o indivíduo em uma posição que lhe garante perceber o mundo de uma outra perspectiva. É na interlocução que leitor e texto se constituem mutuamente, fazendo surgir um novo texto, um novo sujeito e um mundo novo.

Então, para que haja leitura compreensiva, não basta que o indivíduo-leitor decodifique ou identifique os símbolos lingüísticos, mas é indispensável e primordial que ele veja o que as marcas escritas significam, e não o que elas são. É importante que ele privilegie as possíveis relações entre as várias informações vinculadas pelo texto e entre estas e o seu conhecimento de mundo.

Deste modo, a leitura deve ser entendida como uma atividade simbólica específica, que exige a busca e construção de significados que se baseiam no texto, mas que vão além das suas informações explícitas. Assim, a leitura deve ser tomada como uma atividade cognitiva, interativa, construtiva, dialógica, situada e significativa que envolve sempre compreensão: ler é compreender. Esta concepção traz implicada em si a noção de leitor ativo, independente e autônomo. Leitor este que é capaz de ler além da informação-visual, estabelecendo relações entre esta e sua teoria do mundo. Como diz Smith (1999), a leitura depende muito mais do que está por detrás dos olhos do que daquilo que está diante deles: letras, palavras e sentenças.

Então, para compreender um texto, o leitor precisa ativar o seu conhecimento relevante e integrá-lo às informações textuais. Ou seja, ele precisa fazer inferências que podem ser elaboradas tanto a partir da relação das informações no próprio texto, como a partir das relações destas com o seu conhecimento prévio e de mundo.

De acordo com Sperber (1996), as inferências podem ser descritas como atos inteligentes que garantem a junção de informações novas e antigas, favorecendo o surgimento de um dado novo, que no caso da leitura, ocorre a partir do texto 
e de seu contexto. E é justamente a construção dessas relações que faz do texto uma unidade aberta de sentido, que como tal favorece uma multiplicidade de significados dentro do seu horizonte de possibilidades.

É partindo, portanto, da perspectiva da leitura enquanto atividade significativa, que também é adotada por outros autores da área da ciência do texto (Johnson \& Smith, 1981; Marcuschi, 1985, 1989; Oakhill, Cain, \& Yuill, 1997; Oakhill \& Garnham, 1988; Yuill \& Oakhill, 1991), que a habilidade inferencial é concebida aqui como um fator essencial da comunicação e da compreensão em geral.

Em vista disto, pretende-se, neste estudo, vislumbrar o papel da linguagem do pesquisador sobre a construção de inferências de uma criança, em uma situação de diálogo assimétrico caracterizada por uma atividade de compreensão textual composta de uma tarefa do tipo pergunta-resposta. Visa-se verificar a interferência das intervenções lingüísticas da pesquisadora sobre a habilidade da criança para integrar as várias informações disponíveis (conhecimento textual, lingüístico e de mundo) para elaborar uma representação textual coerente e pertinente. Isso será feito com o intuito de tornar evidente a ausência da proclamada neutralidade da linguagem na pesquisa.

\section{Método}

Os dados analisados no presente estudo são oriundos de uma pesquisa sobre compreensão de leitura, realizada a partir da concepção de linguagem como representação mental. Tal estudo fez uso de um procedimento bastante comum em pesquisas sobre compreensão textual: a aplicação a diversos sujeitos de um questionário padronizado sobre um texto, imediatamente após a leitura do mesmo. No entanto, diferentemente desta primeira investigação, o objetivo dentro da atual reflexão é precisamente demonstrar que a linguagem desempenha um papel muito mais ativo no interior de uma pesquisa, do que aquele que lhe era atribuído no trabalho de origem.

Com base nas observações que acabamos de relatar iremos apresentar a análise de um dos questionários/diálogos entre a pesquisadora e um participante.

\section{Participantes}

Foi realizado um estudo de caso (análise de uma sequiência discursiva entre estudante e pesquisadora), cujo participante é uma criança do sexo masculino de dez anos de idade, que faz parte de uma amostra maior (28 alunos) de um estudo originariamente realizado com crianças de $4^{\underline{a}}$ série do Ensino Fundamental de duas escolas da rede particular do Recife.

\section{Material e Procedimento}

Como mencionado na Introdução, os dados analisados neste estudo são oriundos de uma investigação mais ampla desenvolvida por Santa-Clara (2000) ${ }^{2}$, em ambiente escolar. Cada aluno era chamado individualmente em uma sala da escola para realizar uma série de tarefas com vistas à avaliação dos processos envolvidos no desempenho ortográfico, que era o objetivo do estudo em questão. As tarefas utilizadas foram as seguintes: (1) inversão de fonemas, (2) nomeação de numerais, (3) reordenação de frases, números na ordem (4) direta e (5) inversa (WISC), (6) atenção na leitura, (7) correção na leitura e (8) compreensão de texto.

Para o atual estudo de caso, realizou-se um recorte das sessões de diálogo do estudo original, tendo-se como alvo de análise uma tarefa de compreensão. Esta tarefa era composta por um texto narrativo (ver Apêndice A) intitulado: "O desejo de Quipu", acompanhado de sete perguntas de compreensão (ver Apêndice B). A criança era solicitada a ler a narrativa em voz alta e a responder oralmente às perguntas do questionário, ao final da leitura.

Após a leitura do texto indicado, era dada a seguinte instrução pela pesquisadora: "Agora eu vou lhe fazer algumas perguntas sobre essa história, certo?" O texto lido permanecia ao alcance da criança durante toda a tarefa, para que ela pudesse recorrer ao mesmo no momento em que julgasse necessário, ainda que a pesquisadora não fizesse nenhuma menção especial ao fato. As sessões de entrevistas foram gravadas em áudio e posteriormente transcritas em protocolos individuais.

\section{Análise de uma seqüência discursiva}

Nesta investigação, realizou-se uma análise qualitativa dos movimentos discursivos entre criança e pesquisadora, tendo-se como foco a linguagem e o contexto da situação comunicativa. Como diz Koch (2002), o contexto não diz respeito à "situação real", mas a um conjunto de suposições que faz parte do contexto cognitivo dos interlocutores e que é ativado da memória a partir da interação que se estabelece entre eles. Deste modo, cada contexto será diferente de outro, já que sua constituição dependerá da mobilização mnemônica daquilo que é relevante para os participantes. Em vista disto, pretende-se vislumbrar o poder constitutivo da linguagem e do contexto sobre a representação textual da criança no decorrer das trocas de turno entre esta e a pesquisadora, verificando-se as mudanças de representação da criança sobre a narrativa no decorrer da interação.

\section{Extrato de registro}

A criança e a pesquisadora estão sentadas próximas a uma mesa, com o gravador acionado. O texto é então lido pela criança e em seguida a pesquisadora inicia a sessão de perguntas, cujas respostas vai anotando em um protocolo.

1. Pesquisadora: agora, viu Thiago, eu vou. lhe fazer umas perguntes sobre essa história. Pode ficar com o texto agora... Vamos lá? (Aciona cronômetro). "Como era Quipu?",

2. Criança: era um... um ser diferente dos que moravam no seu planeta.

3. Pesquisadora: diferente como ${ }^{4}$

4. Criança: ... tinha os pés nos olhos, ... andava com as mãos,

é ... andava com as mãos para baixo, ...

5. Pesquisadora: (percebendo que o aluno tenta olhar furtivamente o texto) pode olhar o texto! 
6. Criança: ah! tinha corpo coberto.. tinha o corpo coberto de penas coloridas.

7. Pesquisadora: “onde morava Quipu?"

8. Criança: no planeta distante e diferente da Terra.

9. Pesquisadora: "qual era o problema de Quipu?"

10. Criança: que ele queria que todas as pessoas do seu planeta fosse igual a ele.

11. Pesquisadora: "quem construiu a espaçonave?"

12. Criança: ... um grupo de crianças do planeta Terra.

13. Pesquisadora: "como Quipu resolveu seu problema?"

14. Criança: quando viu que tinha várias pessoas semelhantes, igual a ele.

15. Pesquisadora: e quando foi que ele viu isso?

16. Criança: quando... as pessoas da Ter... não. Quando as pessoas da espaçonave desceram. Desceram para o planeta dele.

17. Pesquisadora: "como ele viajou para a Terra?"

18. Criança: contente.

19. Pesquisadora: contente por quê?

20. Criança: porque viu pessoas iguais a ele.

21. Pesquisadora: "quem se parecia com Quipu?"

22. Criança: ... as pessoas que moram na espaçonave. (Olhando o texto o aluno diz:) Aqui não tem.

23. Pesquisadora: e eram de onde?

24. Criança: é... de onde essas pessoas eram?

25. Pesquisadora: hum-hum!

26. Criança: do planeta. Terra.

27. Pesquisadora: OK!

\section{Possibilidade de análise}

Na seqüência discursiva analisada, a não neutralidade da linguagem, da qual se falou até agora, pode ser constatada tanto do ponto de vista da pesquisadora quanto do aluno. Por parte da pesquisadora, isso se verifica pelo acréscimo de intervenções verbais; por parte do aluno, isso se observa pela mudança de uma compreensão equivocada da narrativa para uma compreensão adequada.

Dentre as intervenções da pesquisadora, verificou-se que mais de 50\% de enunciados/intervenções (turnos 3, 5, 15, 19 e 23) eram acréscimos não previstos no roteiro. Tal fato demonstra que a despeito da intenção inicial em se manter fiel ao roteiro pré-estabelecido como forma de controle de variáveis, no momento em que se deu a interação propriamente dita, esta disposição foi alterada.

Uma das possíveis interpretações para este fato está no caráter dinâmico das interações, que se refere à influência de certos aspectos da situação sobre o desenrolar do movimento discursivo. No presente estudo, isto pode ser evidenciado na passagem em que a pesquisadora, baseada na comunicação não-verbal da criança ("olhar furtivo sobre o texto"), sai do roteiro previamente estabelecido, explicitando, no turno 5 , algo que se pensara, inicialmente, deixar na ordem do nãodito: "Pode olhar o texto".

Este movimento furtivo que a criança faz ao dirigir o olhar para o texto lido parece denotar que esta percebe a situação de pesquisa sob a ótica do modelo escolar de comportamento, a situação de teste, na qual não lhe é permitido consultar os textos escolares em geral (livros, cadernos, etc.). A pesquisadora, percebendo esta "manobra" da criança, aparentemente sente a necessidade de intervir verbalmente, deixando claro que ela pode recorrer ao texto caso seja necessário. Note-se que tal possibilidade apenas havia sido deixada implícita, pela presença do texto próximo à criança, não tendo sido declarada em nenhum momento.

Ainda com referência à produção de intervenções verbais alheias àquelas previstas no questionário, foi observado um outro fator desencadeante dentro da interação: sempre que a criança dava uma resposta que não coincidia com aquela esperada pela pesquisadora, esta fazia uma nova intervenção (ou um enunciado, não constante no roteiro). Este fato se mostra contra-exemplificado na sequiência dos turnos 7, 9 e 11, quando a pesquisadora, ao obter respostas esperadas por parte da criança (turnos 8,9 e 12), segue seu roteiro sem alterações.

Deste modo, observa-se que, quando as expectativas da pesquisadora são frustradas, esta se movimenta no sentido de produzir intervenções extras a fim de aproximar a criança da compreensão autorizada pelo autor da narrativa. Isto se verifica, por exemplo, na intervenção realizada no turno 15 ( $E$ quando foi que ele viu isso?) quando à pergunta "Como Quipu resolveu seu problema?" (turno 13), recebe uma resposta vaga ou pouco precisa: "Quando viu que tinha várias pessoas semelhantes, igual a ele" (turno 14).

A resposta que é dada pela criança, no turno 16 ("Quando as pessoas da Ter.. não. Quando as pessoas da espaçonave desceram. Desceram para o planeta dele"), a essa nova intervenção (turno 15), denota a possibilidade de um certo caminhar em direção à compreensão da idéia central da narrativa: o fato de Quipu ser uma criança da Terra e não um ser estranho.

Contudo, a resposta ainda é insegura e imprecisa, fato que parece ser percebido pela pesquisadora, sendo isto observado na sequiência que se dá do turno 17 ao 20 . A resposta dada no turno 18 pela criança: "Contente", à pergunta do roteiro feita pela pesquisadora (turno 17: "Como ele viajou para a Terra?") produz uma nova intervenção extra-roteiro no turno 19 (Contente por quê?). Apesar de tudo, a resposta que é dada pela criança parece ainda avançar pouco em direção à compreensão textual, o que por sua vez irá levar a mais uma intervenção verbal extra por parte da pesquisadora, mais adiante.

Na sequiência, a pesquisadora fez mais uma pergunta pertencente ao roteiro, no turno 21 ("Quem se parecia com Quipu?"). Nesse momento, a criança olha mais uma vez o texto, chegando a verbalizar que não é possível encontrar nele a informação, dando uma resposta imprecisa, no turno 
22 (“...as pessoas que moravam na espaçonave”). A tentativa de buscar no texto a informação e a apresentação de uma reposta imprecisa parecem desencadear na pesquisadora a necessidade de realizar mais uma intervenção extra-roteiro, o que se verifica no turno 23: e eram de onde (essas crianças)?. Nota-se que esta intervenção foi relevante na medida em que fez a criança refletir parafraseando a pesquisadora ("é...de onde essas pessoas eram?"), construindo em seguida a compreensão textual permitida, no turno 24: “(essas pessoas eram) Do planeta. Terra".

Destacou-se até aqui, as intervenções não previamente estabelecidas, incluídas pela pesquisadora, sendo estas tomadas como indício do caráter dinâmico da linguagem, qualquer que seja a situação de interação.

Um outro aspecto relevante dessa demonstração do papel ativo da linguagem da pesquisadora na situação de pesquisa é a transformação da concepção equivocada sobre a personagem central da narrativa, demonstrada pela criança no início dos movimentos discursivos (turno 4: “... tinha os pés nos olhos, ... andava com as mãos, é.. andava com as mãos para baixo, ... ......”) ou seja, a idéia de que Quipu era igual aos habitantes do planeta Xanci (ver Apêndice A), para a concepção de que Quipu era semelhante às pessoas da Terra (turnos: 21 e 29).

Tal transformação é um forte indicativo do poder da linguagem na construção da compreensão textual, pois, aparentemente, as perguntas realizadas pela pesquisadora não se limitaram a possibilitar a explicitação de um conhecimento pronto e acabado, pré-existente na mente da criança. O que se percebe é que a criança vai construindo uma representação textual a partir das intervenções da pesquisadora. A criança cria e recria a sua compreensão de acordo com o movimento discursivo, que lhe permite as idas e vindas sobre as informações que surgem a partir da interlocução texto-adulto-criança. É dentro deste movimento, que a criança reelabora o texto, constituindo-se à medida que modifica a sua compreensão textual.

A presente análise, realizada a partir dos movimentos discursivos ocorridos durante a tarefa de compreensão, revelou o papel ativo (e não neutro) da linguagem através de duas evidências distintas. Em primeiro lugar, houve o que estamos denominando de fuga do roteiro, representada pelo acréscimo de intervenções verbais por parte da pesquisadora em relação ao questionário previamente estabelecido. Notese que isto ocorreu a despeito de uma intenção expressa da mesma de repetir exatamente as mesmas instruções aos diferentes sujeitos como medida de controle de variáveis, ou seja, para que a instrução (expressa através de sua fala) não representasse uma interferência nos resultados da pesquisa. Um outro indício, seguramente o mais importante desse papel ativo da linguagem, foi a própria mudança ocorrida na compreensão da criança, no decorrer da entrevista. Observou-se que mesmo não sendo capaz, inicialmente, de integrar as informações de diferentes partes do texto e/ou do texto com o seu conhecimento de mundo para construir a inferência necessária à compreensão do tema central da narrativa, a criança foi capaz de fazê-lo ao final do questionário.

\section{Considerações Finais}

Os estudos que analisam produtos de aprendizagem, na maioria das vezes tratam a linguagem apenas como um meio de obter dados sobre as competências das crianças, sem considerar o peso da interação entre entrevistador e entrevistado. $\mathrm{Na}$ verdade, as intervenções verbais do pesquisador, enquanto ações discursivas, não são neutras, mas antes modificam os interlocutores durante a interação. Neste estudo, observou-se que o discurso da pesquisadora favoreceu a emergência do "novo", levando a criança a avançar em direção ao conhecimento canônico em questão: a produção de inferências, e, portanto, a compreensão textual.

$\mathrm{Na}$ análise do processo da interação, ficou evidente que a criança foi construindo sua compreensão a partir dos movimentos discursivos entre ela e a pesquisadora, partindo de uma representação inadequada a uma representação textual apropriada, possibilitada pela construção de inferências que, segundo os teóricos da área de compreensão (Johnson \& Smith, 1981; Marcuschi, 1985, 1989; Oakhill, 1984; Oakhill, Cain, \& Yuill, 1997; Oakhill \& Garnham, 1988; Yuill \& Oakhill, 1991), são essenciais para a compreensão em geral, denotando um nível elaborado de interação com o texto.

Através do "suporte" da pesquisadora, a criança constitui o texto, construindo, paralelamente e mesmo ainda de maneira incipiente, a idéia de que a leitura é uma interlocução/ negociação entre leitor e autor via texto. Inicialmente, como é comum entre os leitores iniciantes, a criança entrevistada parecia acreditar na possibilidade de encontrar todas as respostas no texto, porém, a partir das intervenções verbais da pesquisadora, a criança passou a basear-se mais efetivamente no intercruzamento de seu conhecimento de mundo com as informações textuais para construir a sua representação mental do texto. Portanto, o "suporte" da pesquisadora favoreceu o processo de compreensão de texto, pois a interação com a pesquisadora exerceu a função de scaffolding (Bruner,1985), permitindo à criança uma maior consciência da própria leitura pela internalização .

As ações verbais da pesquisadora favoreceram a superação da dificuldade de compreensão inicialmente apresentada pela criança, possibilitando a emergência das múltiplas vozes (Bakhtin, 1992, 2002) necessárias à interlocução entre leitor/autor, que, no caso do leitor-iniciante, precisam ser explicitadas e ativadas a partir das intervenções de um adulto-leitor maduro. Isto porque a consciência sobre a importância do conhecimento de mundo para a efetivação das inferências e, portanto, da compreensão textual são aprendidas na interação entre o aprendiz e um membro social mais capaz, através da linguagem em situações reais de leitura.

\section{Agradecimentos}

Agradecemos o apoio financeiro do CNPq e da CAPES. Agradecemos também as contribuições oferecidas pela Professora Doutora Selma Leitão, da Pós-graduação em Psicologia da Universidade Federal de Pernambuco, para a elaboração deste trabalho. 


\section{Referências}

Bakhtin, M. (1992). Estética da criação verbal. São Paulo: Martins Fontes. Bakhtin, M. (2002). Marxismo e Filosofia da Linguagem. São Paulo: Hucitec. Bruner, J. (1985). Vygotsky: a historical and conceptual perspective. In J. V. Werstsch (Orgs.), Culture, communication and cognition: vygotskian perspectives. Cambridge, Reino Unido: Cambrigde University Press.

Foucambert, J. (1997). A criança, o professor e a leitura. Porto Alegre: Artes Médicas.

Geraldi, J. W. (2000). Prática da leitura na escola. In J. W. Geraldi.(Org.), O texto na sala de aula ( $3^{\mathrm{a}}$ ed., pp. 88-102). São Paulo: Ática.

Johnson, H., \& Smith, L. B. (1981). Children's inferential abilities in the context of reading to understand. Child Development, 52, 1216-1223.

Koch, I. V. (1997). A inter-ação pela linguagem. São Paulo: Contexto.

Koch, I. V. (2002). Desvendando os segredos do texto. São Paulo: Cortez.

Marcuschi, L. A. (1985). Leitura como processo inferencial num universo cultural cognitivo. Leitura, Teoria e Prática, 4, 1-14.

Marcuschi, L. A. (1989). O processo inferencial na compreensão de textos. Relatório Final apresentado ao CNPq (não-publicado), Programa de Pós-graduação em Letras e Lingüística, Universidade Federal de Pernambuco, Recife.

Oakhill, J. (1984). Inferential and memory skills in children's comprehension of stories. British Journal of Educational Psychology, 54, 31-39.

Oakhill, J., Cain, K., \& Yuill, N. (1997). Individual diferences in children's comprehension skill: towards and integraded model. In C. Hulme \& R. M. Joshi (Orgs.), Reading and spelling: development and desorder: Merhwah, New Jersey: Erlbaum.
Oakhill, J., \& Garnham, A. (1988). Becoming a skiller reader. Oxford: Blackwell.

Olson, D. R. (1997). O mundo no papel: as implicações conceituais e cognitivas da leitura e da escrita (Coleção Múltiplas Escritas). São Paulo: Ática.

Orlandi, E. P. (1996). A linguagem e seu funcionamento: as formas do discurso (4⿳亠丷厂 ed.). Campinas, SP: Pontes.

Palangana, I. C. (1994). Desenvolvimento e aprendizagem em Piaget \& Vygotsky (A relevância do social). São Paulo: Plexus.

Palangana, I. C. (2000). A função da linguagem na formação da consciência; reflexões. Cadernos Cedes, 20(35), 19-35.

Santa-Clara, A. M. O. (2000). Um estudo comparativo entre crianças avançadas e crianças atrasadas em ortografia em dois contextos escolares. Dissertação de Mestrado não-publicada, Universidade Federal de Pernambuco, Recife.

Smith, F. (1999). Leitura significativa (3 ${ }^{\underline{a}}$ ed.). Porto Alegre: Artes Médicas.

Smolka, V. (1995). A concepção de linguagem como instrumento: um questionamento sobre práticas discursivas e educação formal. Temas em Psicologia, $\mathrm{n}^{\mathrm{o}} 2$.

Sperber, D. (1996). Entendendo a compreensão verbal. In J. Kahlfa (Org.), A natureza da inteligência: uma visão interdisciplinar. São Paulo: Editora da UNESP.

Valsiner, J. (2000). Culture and human development: an introduction. Londres: Sage.

Vygotsky, L. S. (1996). A formação social da mente: o desenvolvimento dos processos psicológicos superiores. São Paulo: Martins Fontes.

Yuill, N., \& Oakhill, J. (1991). Children's problems in text comprehension: an experimental investigation. Cambrigde: Cambrigde University Press.

1 Como afirma Palangana (2000), o processo de hominização diz respeito à passagem da consciência predominantemente biológica, instintiva para a consciência racional favorecida pela linguagem nas situações sociais.

2 Esta investigação diz respeito à dissertação de Mestrado da referida autora sob a orientação da professora Doutora Lúcia Maria Lins Browne Rego. Tal investigação teve o apoio da instituição de fomento CNPq, sob forma de bolsas de estudo.

3 As perguntas entre aspas fazem parte do roteiro de perguntas pré-estabelecido.

4 As perguntas em itálico fazem parte dos acréscimos feitos pela pesquisadora na situação.

Angela Maria Oliveira Santa-Clara é mestre e doutoranda em Psicologia Cognitiva pela Universidade Federal de Pernambuco. Endereço para correspondência: Pós-Graduação em Psicologia - Universidade Federal de Pernambuco, CFCH, $8^{\circ}$ andar; Rua Acadêmico Hélio Ramos s/n (Cidade Universitária); Recife, PE; CEP 50.670-901. Fones: (81) 3271-8272 e 3271-0599. Fax: (81) 3271-1843. E-mail: angelasantaclara@ yahoo.com.br Tícia Cassiany Ferro, mestre e doutoranda em Psicologia Cognitiva pela Universidade Federal de Pernambuco, é professora assistente na Pontifícia Universidade Católica de Pernambuco. Sandra Patrícia Ataíde Ferreira é mestre e doutoranda em Psicologia Cognitiva pela Universidade Federal de Pernambuco. 